\title{
Hong Kong Physical Education Teachers' Beliefs about Teaching Students with Disabilities: A Qualitative Analysis
}

\author{
Jing $\mathrm{Qi}^{1,2} \&$ Amy Sau Ching $\mathrm{Ha}^{1}$ \\ ${ }^{1}$ Department of Sports Science and Physical Education, The Chinese University of Hong Kong, Hong Kong \\ ${ }^{2}$ School of Physical Education, Ning Xia University, Yinchuan, China \\ Correspondence: Jing Qi, Department of Sports Science and Physical Education, The Chinese University of \\ Hong Kong, Shatin, N.T., Hong Kong. E-mail: qijing@cuhk.edu.hk
}

Received: March 11, $2012 \quad$ Accepted: April 12, $2012 \quad$ Published: July 1, 2012

doi:10.5539/ass.v8n8p3

URL: http://dx.doi.org/10.5539/ass.v8n8p3

\begin{abstract}
This study aims to identify and examine the beliefs of physical education (PE) teachers in Hong Kong toward teaching students with disabilities. Based on the Theory of Planned Behavior (Ajzen, 1991), a qualitative design was employed to examine the underlying beliefs (behavioral, normative, and control) of PE teachers regarding teaching students with disabilities in their mainstream curricular PE. Participants were five Hong Kong PE teachers $(\mathrm{F}=3, \mathrm{M}=2)$. Data were gathered in individual semi-structured interviews, analyzed and presented as descriptive summaries by content analysis (Patton, 2002). Results show that PE teachers intend to implement inclusive practices because of their motivation to comply with inclusive policies and significant referents (SN), and their perceived behavior control (PBC), although they have less than favorable attitudes toward inclusion and toward teaching students with disabilities (AB). These results confirm the importance of subjective norms and perceived behavior control on the decisions of teachers to teach students with disabilities in inclusive PE settings. This study brings to the literature information on the beliefs of PE teachers regarding inclusion and teaching students with disabilities.
\end{abstract}

Keywords: beliefs, inclusion, physical education, theory of planned behavior

Inclusion is a means of increasing participation in learning by all students in order that their educational needs can be met (Barton, 1998; Cheminas, 2000; DePauw \& Doll-Tepper, 2000; Stainback \& Stainback, 1990). Internationally, inclusion has become a common educational practice with support from educational and political advocacy, policy, and legislation (Fitzgerald, 2006). The education of all students within a PE environment presents the teacher with a range of issues beyond the context of a classroom setting, including the physical nature of the activities, the use of specialist areas and equipment, and the dynamics involved in grouping and organizing students within physical activities (Morley, Bailey, Tan, \& Cooke, 2005). It has been suggested that such issues are exacerbated by the presence of a range of students with disabilities (Bailey \& Robertson, 2000). The role of teachers as a facilitator of inclusion and as a manager of the inclusive educational environment is vital (Morley, et al., 2005). In coding and understanding the complexity of teaching, scholars have suggested that greater attention needs to be paid to the teachers' thoughts and actions and how they affect quality teaching (Borko \& Putnam, 1996). Hence, numerous studies have explored teachers' perspectives on inclusive physical education (PE).

A significant portion of this research is driven by a quantitative methodology designed to examine the attitudes of teachers toward teaching students with disabilities. Several student-related and teacher-related variables may influence the attitudes of PE teachers. For example, from the angle of student-related variables, a general agreement exists that teachers had more favorable attitudes toward teaching students with mild disabilities than teaching students with severe disabilities (Block \& Rizzo, 1995; Conatser, Block, \& Lepore, 2000; Conatser, Block, \& Gansneder, 2002; Klavina, 2008; Rizzo \& Vispoel, 1991). Moreover, the type of disability influences the attitudes of teachers. For instance, teachers hold more favorable attitudes toward teaching students with learning disabilities than teaching students with emotional and behavioral disorders (Obrusnikova, 2008; Rizzo \& Vispoel, 1991). From the angle of teacher-related variables, favorable attitudes were associated with female teachers (Conatser, et al., 2000; Meegan \& MacPhail, 2006), more work experiences with students with disabilities (Block \& Rizzo, 1995; Rizzo \& Vispoel, 1991; Tripp \& Rizzo, 2006), educational preparation (Block 
\& Rizzo, 1995; Klavina, 2008; Tripp \& Rizzo, 2006) and perceived competence (Block \& Rizzo, 1995; Conatser, et al., 2002; Obrusnikova, 2008; Rizzo \& Vispoel, 1991; Tripp \& Rizzo, 2006).

A limited number of other studies have also generated interview data to report teachers' perceptions on inclusive PE (Hodge, Ammah, Casebolt, Lamaster, \& O'Sullivan, 2004; LaMaster, Gall, Kinchin, \& Siedentop, 1998; Lienert, Sherrrill, \& Myers, 2001; Morley, et al., 2005; Sato \& Hodge, 2009; Sato, Hodge, Murata, \& Maeda, 2007; Smith, 2004). For example, Sato et al. (2007) described the beliefs of experienced middle school and high school PE teachers in Tokyo regarding teaching students with disabilities. They found that PE teachers had developed beliefs about teaching students with disabilities that fall within a continuum, ranging from favorable (influenced by satisfying experiences) and ambivalent (doubts about the benefits of integration for some students and doubts about their own efficacy) to unfavorable (opposition to the integration students with severe disabilities). Hodge et al. (2004) studied the behaviors and the beliefs of experienced high school PE teachers in suburban school districts in the United States regarding teaching student with disabilities. They found teachers were positively disposed to inclusion as an educational philosophy, but had differential efficacy in achieving successful inclusion and encountered challenges to establishing inclusive practice. Morley et al. (2005) explored the perceptions of secondary school PE teachers regarding the inclusion of children with disabilities. They found that teachers' perceptions regarding inclusion are primarily based on the level of participation that may be achieved by children with disabilities, and that this level is affected by the activity area, level of support, and training opportunities available to them.

\section{Hong Kong Context}

Since the 1970s, the Hong Kong Special Administrative Region (HKSAR) Government has been attempting to move toward the integration of students with special educational needs into ordinary schools (The Hong Kong Government, 1977). For example, the White Paper on Rehabilitation-Integrating the Disabled into the Community: A United Effort (1977) has formulated the policy on rehabilitation and raised increasing concern of the public about the disabled. In 1995, the Hong Kong Government issued the White Paper on Rehabilitation-Equal Opportunities and Full Participation: A Better Tomorrow for All and reaffirmed the policy of integration. At present, the Hong Kong Education Bureau encourages and supports the placement of students with mild to moderate disabilities in mainstream school as much as possible and still intends to retain a range of special schools to meet the needs of those students with severe and complex disabilities (Education Bureau, 2008). Regarding catering to the needs of those with mild to moderate disabilities, mainstream schools are encouraged to adopt a whole-school approach to promote the quality of Hong Kong integrated education by developing three inter-connected dimensions (i.e., school life or culture, policies, and practices). In the 2009-10 academic year, 297 primary schools and 282 secondary schools applied for study support funding (Legislative Council, 2010), which is a significant educational reform advancing the whole-school approach. This move toward integrated education is foreseen to continuously to affect educational decisions across all sectors in Hong Kong in the coming decades (Forlin, 2007). There is little doubt that as the movement toward inclusion progresses, educators will have significantly opportunities to teach students with disabilities in their classes. According to the Whole School Approach to Integrated Education Operation Guide (Education Bureau, 2008), students with disabilities or/and special educational needs (SEN) are, generally those who need special educational support because they have learning disabilities in one way or other. The major types of disabilities or SEN include special learning disabilities in reading and writing, metal retardation, autism, attention deficit and hyperactivity disorder (ADHD), physical handicap, visual impairment, hearing impairment, and communication disabilities. In this study, the term 'students with disabilities' is used to mean students with SEN or/and disabilities.

With regard to inclusive educational practices, several local studies have revealed that Hong Kong teachers, who are involved in the movement toward inclusion, have strong commitment to inclusion and are optimistic about the benefits they observed in social interactions among students as well as in creating a receptive culture in schools (Crawford, Heung, Yip, Yuen, \& Yim, 1999; Forlin, 2007; Wong, Pearson, \& Lo, 2004; Yuen \& Westwood, 2001). However research in the area of PE is significantly limited. Only one study compared the attitudes of pre-service and in-service PE teachers toward inclusion and toward teaching students with disabilities in Hong Kong and Mainland China. Accordingly, both pre-service and in-service teachers philosophically support inclusion, but numerous concerns and different opinions exist. For example, most teachers disagree with the inclusion of students with severe disabilities into regular PE classes. From Sato et al. (2007), Morley et al. (2005), and Hodge et al. (2004) we have studied the perceptions and beliefs of PE teachers regarding inclusion in Japan, United Kingdom, and United States, respectively. However, only a few studies on the beliefs of PE teachers in Hong Kong regarding inclusion and teaching students with disabilities have been 
published. Taking cue from the research gap, this study aimed to examine the beliefs of PE teachers in Hong Kong toward teaching students with disabilities.

\section{Theoretical Framework}

The theory of planned behavior (TPB) (Ajzen, 1985, 1991, 2005) served as the theoretical basis for this study (see Figure 1). According to the TPB, volitional human behavior is immediately preceded by intention to engage in this behavior. Behavioral intention is predicted, in turn, by three main determinants: attitude toward the behavior (AB), subjective norm (SN), and perceived behavioral control (PBC). The extent to which individuals view a particular behavior positively (attitude), think that significant others want them to engage in the behavior (subjective norm), and believe that they are able to perform the behavior (perceived behavioral control), serve as direct determinants of the strength of their intention to carry out the behavior.

Each of these three direct determinants of behavioral intention is influenced, in turn, by an indirect determinant. Indirect determinants are based on a set of salient beliefs and evaluations of these beliefs. Salient behavioral beliefs about the outcomes of a particular behavior, as well as evaluations of these outcomes, produce an 'attitude toward the behavior (AB)'. Salient normative beliefs about whether important others approve of the behavior, as well as the individual's motivation to comply with these perceived norms, constitute a 'subjective norm (SN)'. Salient control beliefs about facilitators of or obstacles to performing the behavior (such as skills, resources, opportunities, etc.), as well as the strength of each of these beliefs, determines 'perceived behavioral control (PBC)'. In combination, $\mathrm{AB}, \mathrm{SN}$ and $\mathrm{PBC}$ lead to the formation of a behavioral intention. As a general rule, the more positive the attitude and subjective norm and the stronger the perceived behavioral control, the greater the intention will be for the individual to perform the behavior in question (Ajzen \& Cote, 2008, p. 301).

The TPB has been used to explain teachers' intentions and behavior in the classroom, such as teacher beliefs and behavior in portfolio assessment (Schaaf, Stokking, \& Verloop, 2008), teachers' adoption of new technology (Sugar, Crawley, \& Fine, 2004), and teachers' beliefs concerning constructivist teaching practices (Haney \& McArthur, 2002).

The TPB has also been used to evaluate physical education teachers' attitudes, intentions, and actual teaching behaviors, such as predicting PE teachers' intentions to offer physical active PE classes (Martin \& Kulinna, 2004), and examining teachers' intentions toward teaching physical activity lessons and their actual behavior in the PE classes (Martin \& Kulinna, 2005). In particular, the TPB has been utilized in describing PE teachers' beliefs and intentions toward teaching students with disabilities in inclusive PE settings (Conatser, et al., 2002; Hodge, et al., 2004; Sato \& Hodge, 2009; Sato, et al., 2007). For example, Conatser et al. (2002) conducted a quantitative methodology and concluded that teachers' perceived behavior control and attitudes predicted their intentions toward teaching students with disabilities. Hodge et al. (2004), Sato and Hodge (2009), and Sato et al. (2007) were descriptive and qualitative. These studies bring to the literature information on PE teachers beliefs and intentions about the inclusion and teaching students with disabilities. Results of these studies have the potential to help guide approaches to facilitate inclusive implementations in PE.

Based on the TPB, this study aims to identify the underlying beliefs (behavioral, normative, and control) of PE teachers regarding teaching students with disabilities in their mainstream curricular PE. This information provided the basis for the understanding teachers' intentions to teach students with disabilities.

\section{Method}

\subsection{Participants}

Purposeful sampling (Patton, 2002) was used to select 5 secondary PE teachers from Hong Kong. Intensity sampling strategy of purposeful sampling was conducted in this study. Using the logic of intensity sampling, one seeks excellent or rich examples of the phenomenon of interest (e.g., experienced Hong Kong PE teachers who have taught students with disabilities), but not extremely or highly unusual cases (Patton, 2002). "Intensity sampling involves some prior information and considerable judgment" (Patton, 2002, p. 234). Selection of the teachers was based on criteria that paralleled those identified by Sato et al. (2007) and Hodge et al. (2004). First, all of them are PE teachers whose schools locate in New Territories and Kowloon of Hong Kong. Second, they are experienced teachers teaching PE at the secondary school level. Third, they have established reputations as effective teachers within their respective school districts. Fourth, they have at least five years of teaching experience in their schools. These criteria were used to ensure that the teachers have already reached to the 'maturity' stage of development (Katz, 1972). At this stage, 'teachers begin to ask questions of themselves and their teaching that focus on their insights, perspectives, and beliefs regarding teaching and children' (Stroot, 1996, p. 342). Participants could reflect on their experiences on teaching students with disabilities. Fifth, the 
teachers have taught classes composed of students without disabilities and at least one student with mild to severe disabilities.

Five teachers were contacted by email and asked if they are willing to participate in an inclusion study. All five teachers agreed and completed a follow-up demographic questionnaire. The questionnaire was concerning personal and their PE classes information (gender, age, education, taught grade, years of teaching PE, years of teaching inclusive PE, class size, coursework in adapted physical education, the type and number of students with disabilities). Then the five teachers were recruited to be the information-rich cases and were conducted the follow-up interviews. In this study, all five teachers are teaching classes composed of students without disabilities and at least one student with a disability (Grade 1 to Grade 7). Table 1 presents demographic data specific to teachers and students with disabilities. Pseudonyms are used to protect the privacy and anonymity of all teachers.

Table 1. Demographic information on teachers and their PE classes

\begin{tabular}{cccccl}
\hline Teacher & Gender & Age & $\begin{array}{c}\text { Years } \\
\text { experience } \\
\text { teaching PE }\end{array}$ & Class size & \multicolumn{1}{c}{$\begin{array}{c}\text { Disability types of students } \\
\text { (no. in class) }\end{array}$} \\
\hline YING & F & 42 & 22 & 30 & $\begin{array}{l}\text { Hearing impairment (1), Visual } \\
\text { impairment (1) } \\
\text { Autism (1), Attention Deficit }\end{array}$ \\
LE & M & 36 & 14 & 40 & $\begin{array}{l}\text { Hyperactivity Disorder (ADHD) (1), } \\
\text { Visual impairment (1) }\end{array}$ \\
YOU & M & 43 & 20 & $35-47$ & $\begin{array}{l}\text { Autism (1), ADHD (1) } \\
\text { ADHD (1), Infantile paralysis (1) } \\
\text { XIA }\end{array}$ F \\
YI & F & 34 & 9 & 40 & $\begin{array}{l}\text { Physical impairment: legs handicapped } \\
\text { (1), Autism (1) }\end{array}$ \\
\hline
\end{tabular}

\subsection{Data Collection}

Semi-structured interviews (Patton, 2002) were conducted with participants in their respective schools. Prior to the interviews, the participants were contacted via electronic mail to arrange and conform the date, time, and location of interviews. One-on-one interviews were scheduled to avoid interference with the teaching schedules or important commitments of participants and to ensure that there is sufficient time for data clarification, elaboration, and evaluation. An interview guide was prepared, providing a framework for developing questions, sequencing questions, and deciding on which information requires greater consideration (Patton, 2002). Based on the format specified by Aizen (2002), literature review, research purpose, and expert opinions, the central interviews were designed to capture underlying beliefs of teachers relevant to teaching students with disabilities. Participants were asked what they perceived to be the benefits and the drawbacks of inclusion and teaching students with disabilities (attitudes), who would motivate and who would frustrate of them complying with inclusion policy and implementing teaching practices, and what factors make it easier and more difficult for them to teach students with disabilities in their mainstream PE classes (PBC).

All interview sessions lasted approximately 60 minutes and, with permission from the interviewees, were recorded on audio tape. During the interviews, key phrases, lists of major points made by the respondent and important quotations were documented to facilitate post-analysis. Interview transcripts varied in length, ranging from eight to ten double-spaced pages.

\subsection{Data Analysis}

Interview data of this study were subjected to content analysis and organized and reported by using analytical framework approaches (Patton, 2002). Analytical framework approaches begins with an analyst's deduced propositions and then the researcher begins by examining the data. Following the analytical framework, the preparation, organization, and analysis of the interview data included five steps. First, after each interview, the researcher immediately transcribed the data and verified the data and tentative interpretations with the interviewee for accuracy and clarification on unclear areas. According to interviewees' comments, the researcher made minor fine-tuning to better capture their perspectives. Second, a systematic coding scheme made up of categories was developed from the TPB framework and review of the utilization literature. Third, data was coded according to the categories and schemes. Fourth, organizing and describing what has been collected from the interview data. Fifth, constructing interpretation, making comparisons with previous studies, and drew conclusions. 


\subsection{Trustworthiness}

The trustworthiness of this study was established using three layer of strategies, namely, peer review (Creswell, 2007; Lincoln \& Guba, 1985; Merriam, 2009), member checks (Merriam, 2009), and rich, and thick description (Merriam, 2009). A member checks was employed in this study for ensuring internal validity of credibility. In this study, participants indicated that the manuscript correctly reflected their meanings and opinions after making minor fine-tuning. Peer review provides an external check of the research. In this study, the peer reviewer was an experienced qualitative researcher. Throughout data collection and analysis, the role of peer reviewer was to read and comments on the researchers' logic of interpretations, to question the themes and issues the researchers pulled, or potentially overlooked, from the transcribed interview data. Rich, thick description was employed for enhancing the possibility of the results of a qualitative study "transferring" to another setting. In this study, specific information on every participant and their classes was presented. During interpreting and reporting data, thick description of findings was supported by adequate evidence in forms of quotes.

\section{Results}

In the following section, the results from semi-structured interview were organized and reported according to the TPB components.

\subsection{Behavioral Beliefs}

Generally, participants have expressed less than favorable attitudes toward teaching students with disabilities in their mainstream PE classes. They have identified six salient beliefs that are representative of their perceptions regarding the outcomes (positive and negative) of the behavior of teaching students with disabilities:

Offering equal chances for all students to engage in regular PE classes;

Improving the social competence of students with and without disabilities;

Damaging the self-esteem and self-confidences of students with disabilities;

Hindering the motor skill development of students with disabilities;

Dampening the confidence of teachers; and

Decelerating teaching schedules and disrupting teaching practices.

All five teachers agree that the concept of inclusion is good and ideal. For example,

MISS Ying: I think it's good for government to implement inclusion...It's really about giving equal opportunities, regardless of their ability and needs. Actually, during this process, all students, with and without disabilities, can develop their social ability. Students with disabilities enter the mainstream school and get new friends without disabilities. Students without disabilities still feel self-satisfied by offering help to their disabled peers.

Although inclusion is a good concept associated with equality and all students socially benefit from it, teachers claim that inclusion has negative impacts on students with disabilities (e.g., it hurts their self-esteem and self-confidences). Teachers believe that inclusion is unfair to students with disabilities. For example,

MISS YING: It's so unfair to him (a student with hearing impairment). When trying to follow instructions, he totally does not understand. It's obvious that he is trying his best to follow my words and match up to his peers, but he fails all the time even when I give him extra help by explaining clearly. I can feel that he is so embarrassed and frustrated.

MR. LE: It is miserable for him (an autistic student). He didn't understand my words and he can't perform the designated movements. Sometimes he just does his own thing and speaks randomly. Sometimes he is teased by his classmates. I think this has a negative effect on his confidence. Also, when using pair-up strategy in class, nobody is willing to pair with him at the beginning, although I arrange for an obedient student to pair with him. You can feel that he is hurt.

Meanwhile, teachers consider that the implementation of inclusive PE actually hinders the motor skill development of disabled students. For example,

MISS YING: I doubt it is really meaningful for him (a student with visual impairment) because there are so many activities he cannot do, such as basketball, football, games among others. I believe that he would be better educated in individualized programs, such as traditional special classes. Perhaps, the special physical educational programs he received in a special school would be better for his physical development.

Three teachers assert that teaching students with disabilities has negative impacts on their own confidences in 
teaching PE. They feel ill-prepared when they are not notified in advance of the presence of students with disabilities in their classes. Furthermore, teachers also feel they have inadequate academic preparation and professional knowledge relevant to teaching disabled students. These, in turn adversely affect their confidence in teaching. For example,

MISS YING: Sometimes I do not know the true disability at the beginning of the class. I feel frustrated because I can't teach that student with hearing impairment. Furthermore, I do not have confidence to teach all activities to disabled students. I doubt that I could provide appropriated instructions for all students.

In addition to dampening the confidence of teachers in teaching, inclusive PE decelerates teaching schedules and disrupts teaching practices. For example,

MR. LE: I pay more time and attention to get that autistic student engaged in class activities, but the process of inclusion slows down the whole teaching plan. It's really difficult to adjust the whole program to fulfill the needs of one or two student with disabilities.

\subsection{Normative Beliefs}

Participants perceived inclusive education policies, school administrators, and coworkers (e.g., peers and social workers) as the significant referents to motivate them to perform the inclusive teaching practices. All teachers were motivated by the beliefs of professional teaching role and the willingness to comply with those in their school (administrators, peers, and social workers) and educational policies relevant to inclusion as much as possible. Accordingly, "no one expresses disagreement" over the implementation of inclusive PE. In addition, students with and without disabilities, and their parents also are the motivators which influence their performing the behavior of teaching students with disabilities.

MS. YING: My school follows the governments' inclusive policies and includes the students with various disabilities. So as a PE teacher, I must follow the school's policy and teach them. I treat them as 'normal' students and try my best to meet their learning needs.

The teachers get useful support from their own schools. Teachers were motivated to comply with their coworkers' suggestions about how to treat students with disabilities by communicating with school administrators, peers, and social workers in school meetings or informal talking. Teachers' acquired instructional, managerial, and behavioral information enhance their efficacy in teaching students with disabilities.

MR LE: Within our own school, we have physical education panel meetings at the beginning of the term where we get together to talk about how to deal with students with disabilities (e.g., type and characteristics of students, effective strategies, and decisions on what to do next). After participating in these meetings, I feel confident to teach students with disabilities. These kinds of communications and collaborations make me feel good in implementing inclusive practices.

The five teachers also claim that they get useful support from communicating with social workers in their schools.

MISS XIA: I always communicate with the social worker of our school to know the detailed characteristics of a student with ADHD. The social worker knows more information than teachers because she has been paying attention to the problems of this student and keeping contact with the parents of the student. When I face difficulties in teaching this student, I talk with the social worker to find information relevant to possible solutions.

In addition, students with and without disabilities, and their parents, also are influences that put teachers pressure to implement inclusive teaching practices. For example, three teachers indicated that they are not sure if the students with disabilities really want to be included into the mainstream schools and curriculum. Students without disabilities also serve as an important referent, helping or hindering in the implementation of inclusive PE. Teachers report that most students without disabilities welcome their peers with disabilities and intend to engage in class activities with them. However, there have been the issues of bullying among students with and without disabilities. The excluding attitudes of students without disabilities hinder teachers' inclusive teaching practices.

MR YOU: The students without disabilities are helpful and accepting of their classmates with disabilities. Their positive and kindly attitudes support my teaching practices. I don't need spare time to persuade the students without disabilities to pair up with their peers with disabilities. When an autistic student is not able to control his behavior, the helpful performances of his classmates without disabilities make me confident to teach such student. 
MR. LE: I have a student with autism. When he can't express himself effectively, his fellow classmates without disabilities often laugh at them or bully him. It's a difficulty to teach students with disabilities to embrace their disabled peers......

The parents of students with and without disabilities also influence teachers' implementation of inclusive practices. For example, the parents of students with disabilities generally wouldn't like to admit the fact that their children belong to the disabled group. At the same time, one of teachers expresses that the negative attitudes of parents of students without disabilities toward inclusion take pressure to his teaching in PE class. In a word, the unwillingness of the parents of students with disabilities to offer detailed information about their children and the negative attitudes of parents of students without disabilities hinder teachers' actual inclusive teaching practices.

\subsection{Control Beliefs}

The teachers in this study have identified class size, time, the type and severity of student's disability, the motivation of students with disabilities, the attitudes of students without disabilities, interaction with peers, and prior notification of presence of student with a disability as external factors that might aid or hinder their inclusive teaching practices. In addition, teachers' teaching experiences and professional knowledge relevant to teaching disabled individuals have been identified to be the personal factors which can facilitate and impede their inclusive implementations.

For all five teachers, the issues of class size and time are the two main strong themes emerged from the data. Teachers consider that in inclusive PE settings, having reasonable class sizes and staff ratios is more important than having adequate facilities or equipment for teaching students with disabilities. Consequently, teachers indicate that they have no quality time to give individualized attention to students with disabilities. For example,

MR. YOU: It doesn't matter if we have sufficient equipment in teaching. You know, we don't need to teach very difficult skills to students. However it's very important to have a smaller class size and staffing ratio. I try my best to deal with the present situation in which one or two students with disabilities are in a class of around forty students, but I can't give individualized attention and quality time to many students with disabilities and provide appropriate instructions for all students.

MR. LE: I can't keep my eye on more than one or two students with disabilities. I have regular students also. I am responsible for everybody in my PE class, not just students with disabilities.

The type of disability is a challenge for at least three teachers. Three teachers have expressed different views on teaching students with different types of disability. Mr. Le tends to have a more favorable attitude toward teaching "mentally" than "physically" disabled students. This is inconsistent with the attitudes of Miss Xia and Miss Yi. For example,

MR. LE: I think mentally disabled students can finish movements as long as they can understand. They can understand and follow your instructions if you give them more special care, while "physically" disabled students cannot practice some programs, like basketball. It is better to let "physically" disabled students receive special programs in separate schools. If included into a general school, it would be better, from a PE perspective, to let them go to the library to become helpers.

On the contrary, Miss Xia and Miss Yi point out that there is no big deal in fulfilling the learning objectives of a "physically" disabled student by adapting and modifying the learning environment.

MISS XIA: By knowing their skills and abilities, it's easy for teachers to choose modified equipment and programs to develop the skills of a student with a disability. However there are more problems in controlling behavior for a "mentally" disabled student. It would be better that they receive professional and one-to-one special care.

MISS YI: It's difficult to handle the behavior of a mentally disabled student because I'm not very sure that I can deal with his problem all the time.

Furthermore, for all five teachers, teaching students with severe disabilities is the most challenging practice. The five teachers disagree over the inclusion and teaching of students with severe disabilities in regular PE classes. Although there are few students with severe disabilities in the classes of these teachers, they all report that the process of teaching students with severe disabilities demands a significant portion of the time of the teacher due to the individualized attention required by these students.

MISS YING: All students should have an opportunity to get equal education, but for some students with severe disabilities, inclusion is problematic. There is a student with severe visual impairment that really has a tough time. His disability hinders his full participation in activities. I cannot pay attention to him all the time, and I am 
afraid that I cannot teach him. I think that students with severe disabilities need to go to special classes to get appropriate individualized instructions.

The third strong theme that greatly concerns teachers is the lack of motivation to engage in class activities among disabled students.

MISS XIA: Following the school's policy, I welcome students with disabilities to attend my class as long as they are supported by their parents. However I found that the students don't always want to take part in class activities. He (an autistic student) worries about being laughed at by other classmates. He is afraid that he can't keep up with the teaching schedule. He refuses to join for no particular reason. Sometimes, I feel that he just wants the PE class to end as fast as possible. His appearance worries me.

MISS YI: Even if teachers try very hard to encourage him (a student with ADHD) and his peers are willing to help him, he still does not want to take part in class activities. He is unwilling to cooperate.

However, teachers point out that not all students without disabilities are welcome their disabled peers to study together with them; some often laugh at them and bully them. The excluding attitudes of students without disabilities toward their disabled peers make teachers feel difficult to implement inclusive PE.

Although there are numerous concerns of inclusion, teachers also get supports in the school level. All teachers believed that communication with administrators and peers and prior notification of the inclusion of students with disabilities could enhance their efficacy.

In terms of personal circumstances, teachers referred to factors such as teaching experiences and professional knowledge relevant to teaching disabled individuals as facilitating or impeding their inclusive implementations.

The substantial teaching experiences in tackling individual differences is the most personal factor that can facilitate the implementation of inclusive PE. Teachers report that teaching experiences involving individual differences play a vital role in gaining confidence in teaching students with disabilities. Experienced teachers know how to deal with specific situations that occur in their PE classes because they always encounter highly diverse classes. They treat disabled students as low-ability individuals. In turn, they are confident in teaching them in their regular classes.

MISS YING: I have lots of teaching experience to enable me to tackle individual differences. I just treat students with mild disabilities as "normal students." I think I have enough experience to deal with a child with a disability. I understand the characteristics of these students and I arrange proper instructional environments for them. A child's mother really appreciates that I made PE lessons appropriate for her child with some kind of heart disease. She told me that her son enjoys PE class.

MR. YOU: I think experience is needed to accumulate confidence. At the beginning of the inclusion policy, I was not particularly sure of the real situation of students with disabilities, but I had the confidence to deal with it slowly because I have many years of teaching experience. It's not so difficult to include students with mild disabilities. My confidence increased with time and with accumulated experiences on teaching them.

Emerged from the teachers' interview data, the second personal factors that can influence inclusive teaching practices is their professional knowledge about how to teach individuals with disabilities. With the trend toward inclusion, three teachers express that they feel lack of professional knowledge and need to acquire information or training opportunities on how to teach students with disabilities effectively. Four teachers didn't take the course of adapted physical education (APE) during their academic preparations nor did they receive special in-service trainings on teaching PE to students with disabilities. The purpose of this course is to enable students to understand how physical education or sport can be individualized to meet the special need of students who are challenged by impairments or disorders. For example, Mr. You claims that in Hong Kong, the support for inclusion in the PE area is limited.

MR. YOU: At present, we can all handle the inclusion of students with mild disabilities. Within the physical education department, we hold group meetings regularly to talk about students with disabilities. We can get support from our own teaching experiences, but there is a need to get more information to teach them effectively if these cases are going to become more common.

However, the teacher who took the coursework of APE indicates that she can't construct the connections between the program and the actual assignment of teaching students with disabilities in a large inclusive class.

\section{Discussion}

For purpose of this study, the theory of planned behavior (Ajzen, 1985, 1991, 2002) provides apposite framework for understanding the beliefs of PE teachers to teach students with disabilities. 
First, teachers hold less than favorable attitudes based on the several salient behavioral beliefs about the behavior of teaching students with disabilities. This finding is in accord with the accessible beliefs about the consequences of the TPB (Ajzen, 1991, 2002) and consistent with related research by Sato and Hodge (2009). However, Hodge et al. (2004) and Conatser et al. (2002) reported that teachers were positively disposed to inclusion. Sato et al. (2007) found that teachers had developed behavioral beliefs (ranging from favorable, ambivalent, to unfavorable) based on the degree to which they encountered difficulties teaching in inclusive classes. According to Ajzen (2005), the attitude toward the behavior is determined by the person's evaluation of the outcomes associated with the behavior and by the strength of these associations. Participants in this study hold less than favorable attitudes because they believe that including students with disabilities into their mainstream curricular PE leads to mostly negative outcomes, such as damaging the self-esteem of disabled students, hindering the motor skill development of disabled students, and so on.

Second, teachers are motivated to comply with inclusive educational policies and significant referents (e.g., school administrators and coworkers) and intend to implement inclusive practices. This finding is also in accord with the accessible beliefs about the subjective norms of the TPB (Ajzen, 1991, 2002) and consistent with previous studies (Hodge, et al., 2004; Sato \& Hodge, 2009). Results show that teachers intend to teach students with disabilities by following government's and school's policies on inclusion and complying with their coworker's practices and suggestions, although they hold less than favorable attitudes. Comparing with previous studies, the social worker is first mentioned as one referent that may help PE teachers decide to teach student with disabilities. In Hong Kong, school social work service has existed for more than 30 years, and the policy of "one school social worker for each secondary school" was implemented in 2000 (To, 2007). Teachers can get more personal information on students with disabilities from social workers who concentrate on helping students adjust in schools and who know more about the characteristics of students with disabilities.

Third, control beliefs are concerned with the presence or absence of factors that can facilitate or impede the performance of a particular behavior (Ajzen \& Cote, 2008). Specifically, the role of control beliefs is illustrated in this study; it deals with teaching disabled students. Numerous factors can help or hinder teaching of students with disabilities. These potential facilitators and inhibitors were also partly reported by Sato et al. (2007), Morley et al. (2005), Hodge et al. (2004), Lienert et al. (2001), and LaMaster et al. (1998). The more necessary resources and support or knowledge teachers believe they possess, and the fewer difficulties or impediments they anticipate, the greater is their perceived control over the behavior of teaching students with disabilities. These factors can influence the degree of control a teacher teaches students with disabilities in his/her PE class.

Stated differently, five potential facilitating factors mentioned frequently were teachers' substantial experience on tackling individual differences, possession of professional knowledge relevant to teaching disabled students, interaction with peers and school administrators, availability of help from the students without disabilities, and prior notification of presence of students with a disability. According to Ajzen (2005), control beliefs may be based in part on past experience with the behavior. Based on their own past work experiences, teachers have substantial teaching experience to tackle individual differences. This constructs their confidences to meet the challenge of inclusion. At the same time, these beliefs are also usually influenced by second-hand information about the behavior, which comes from an observation of the experiences of acquaintances and friends, and by other factors that increase or reduce the perceived difficulty of performing the behavior in question (Ajzen, 2005). For example, teachers get relevant useful information and then improve their control beliefs of teaching students with disabilities through interacting with school administrators, peers, and social workers. In addition, getting support from students without disabilities and school prior messages relevant to the presence of students with disabilities, also make teachers perform the behavior of teaching disabled students well. These findings support the notion that the more the attainment of a behavioral goal is considered to be under an individual's volition, the stronger the association with an intention to perform the behavior (Ajzen, 2005; Conatser, et al., 2002; Hodge, et al., 2004). Furthermore, teachers experienced limited initial teaching training and continuing professional development (CPD) opportunities relevant to teaching students with disabilities. This finding is consistent with previous studies by Morley et al. (2005), Smith and Green (2004), and LaMaster et al. (1998). Therefore, the availability of in-service training about how to teach disabled students relevant to a PE-specific context for teachers is mentioned once again in this study. In turn, research on how teachers' inclusive pedagogical knowledge developed is need. As to relevant initial teaching training, Hodge et al. (2002) points that acquiring adequate physical education teacher education (PETE) training relevant to teaching students with disabilities enhances teachers' perceived competences toward inclusive practices. However, the effect of the APE program is not sure in this study. Therefore, there is a need to examine the views of teachers who completed the APE coursework of its effects. In addition, more discussion with teachers who took the APE 
program on how to construct the relationship between the program and the actual teaching situation would perhaps yield richer data that would offer implications for PETE providers.

Five frequently mentioned factors whose presence would hamper teaching disabled students were large class size, limited time, the type and severity of student disabilities, lack of motivation among disabled students to participate in PE classes, and the excluding attitudes of students without disabilities. Sherrill (1998) noted that class sizes larger than 30 when working with students with disabilities contributes to teacher burn out, intensifies discipline problems, and is a barrier to individualizing physical education instruction. Therefore, school organization should consider modifying class size for meeting the inclusion challenges. For the lack of motivation of students with disabilities to engage in class activities, more qualitative research is needed to conduct to examine the perceptions of students with disabilities about their being included into the mainstream curricular PE. The qualitative data would helpful for teachers' modified teaching practices and further inclusion of them. According to Ajzen and Cote (2008), each control belief contributes to a perceived behavioral control, in direct proportion to the perceived power of the factors to facilitate or impede the performance of the behavior. Therefore, the more teachers foster potential facilitating factors and deal with potential inhibiting factors in their inclusive teaching practices, the stronger are their intentions to include and to teach students with disabilities, and the higher are the behaviors they actually conduct.

\section{Conclusions}

Based on the theory of planned behavior, this study used a qualitative approach to elicit and code readily accessible beliefs of teachers toward teaching students with disabilities. Results show that PE teachers intend to implement inclusive practices because of their motivation to comply with inclusive policies and significant referents $(\mathrm{SN})$, and their perceived behavior control ( $\mathrm{PBC})$, although they have less than favorable attitudes toward inclusion and toward teaching students with disabilities (AB). These results confirm the importance of subjective norms and perceived behavior control on the decisions of teachers to teach students with disabilities in inclusive PE settings.

This study brings to the literature information on the beliefs of PE teachers regarding inclusion and teaching students with disabilities in Hong Kong. A primary target for future research is exploring how attitudes may be changed toward teaching students with disabilities and examining the extent to which certain factors influence intentions - to more accurately find the best method for increasing the confidence of PE teachers in the inclusion process and in teaching students with disabilities.

\section{References}

Ajzen, I. (1985). From intentions to action: a theory of planned behavior. In J.Kuhl \& J. Beckmann (Eds.), Action-control from cognition to behavior (pp. 11-19). Heidelberg, Springer.

Ajzen, I. (1991). The theory of planned behavior. Organizational Behavior and Human Decision Processes, 50(2), 179-211. http://dx.doi.org/10.1016/0749-5978(91)90020-T

Ajzen, I. (2002). Constructing a TpB questionnaire: Conceptual and methodological considerations. Retrieved from http://www.people.umass.edu/aizen/Tpb.html

Ajzen, I. (2005). Attitudes, personality, and behavior (2nd ed). Milton-Keyness, Eng: Open University Press.

Ajzen, I., \& Cote, N. G. (2008). Attitudes and the prediction of behavior. In W. D. Crano \& R. Prislin (Eds.), Attitudes and attitude change. New York: Psychology Press.

Bailey, R., \& Robertson, C. (2000). Including all pupils in primary physical education. In R. P. Bailey \& T. M. Macfadyen (Eds.), Teaching physical education (pp. 5-11). London: Continuum.

Barton, L. (1998). The politics of special educational needs. Lewes: The Falmer Press.

Block, M. E., \& Rizzo, T. L. (1995). Attitudes and attributes of physical educators associated with teaching individuals with severe and profound disabilities. Journal of the Association for Persons with Severe Handicaps, 20(1), 80-87.

Borko, H., \& Putnam, R. (1996). Learning to teach. In D. C. Berliner \& R. C. Calfee (Eds.), Handbook of educational psychology (pp. 673-709). New York: Macmillan.

Cheminas, R. (2000). Special education needs for newly qualified and student teachers. London: David Futon Publishers.

Conatser, P., Block, M., \& Lepore, M. (2000). Aquatic instructors' attitudes toward teaching students with disabilities. Adapted Physical Activity Quarterly, 17(2), 197-207. 
Conatser, P., Block, M. E., \& Gansneder, B. (2002). Aquatic instructors' beliefs toward inclusion: The theory of planned behavior. Adapted Physical Activity Quarterly, 19(2), 172-187.

Crawford, N., Heung, V., Yip, E., Yuen, C., \& Yim, S. (1999). Integration in Hong Kong: where are we now and what do we need to do? A review of the Hong Kong government's pilot project. Hong Kong Special Education Forum, 2(3), 1-13.

Creswell, J. W. (2007). Qualitative inquiry and research method: Choosing among five approaches $\left(2^{\text {nd }}\right.$ ed.). Thousand Oaks, CA: Sage.

DePauw, K. P., \& Doll-Tepper, G. (2000). Toward progressive inclusion and acceptance: Myth or reality? The inclusion debate and bandwagon discourse. Adapted Physical Activity Quarterly, 17(2), 135-143.

Education Bureau. (2008). Whole School Approach to Integrated Education Operation Guide.

Fitzgerald, H. (2006). Disability and physical education. In D. Kirk, D. Macdonald \& M. O'Sullivan (Eds.), The Handbook of Physical Education. London: Sage Publications.

Forlin, C. L. (2007). Inclusive educational practices: A way forward for Hong Kong. Chinese Education and Society, 40(4), 63-75. http://dx.doi.org/10.2753/CED1061-1932400405

Haney, J. J., \& McArthur, J. (2002). Four case studies of prospective science teachers' beliefs concerning constructivist teaching practices. Science Education, 86(6), 783-802. http://dx.doi.org/10.1002/sce.10038

Hodge, S. R., Ammah, J. O. A., Casebolt, K., Lamaster, K., \& O'Sullivan, M. (2004). High school general physical education teachers' behaviors and beliefs associated with inclusion. Sport Education and Society, 9(3), 395-419. http://dx.doi.org/10.1080/13573320412331302458

Katz, L. G. (1972). Developmental stages of preschool teachers. Elementary School Journal, 73(1), 50-54. http://dx.doi.org/10.1086/460731

Klavina, A. (2008). Using peer-mediated instructions for students with severe and multiple disabilities in inclusive physical education: A multiple case study. European Journal of Adapted Physical Activity, 1(2), 7-19.

LaMaster, K., Gall, K., Kinchin, G., \& Siedentop, D. (1998). Inclusion practices of effective elementary specialists. Adapted Physical Activity Quarterly, 15(1), 64-81.

Legislative Council. (2010). The Hong Kong Legislative Council.

Lienert, C., Sherrrill, C., \& Myers, B. (2001). Physical educators' concerns about integrating children with disabilities: A cross-cultural comparison. Adapted Physical Activity Quarterly, 18(1), 1-17.

Lincoln, Y. S., \& Guba, E. G. (1985). Naturalistic inquiry. Thousand Oaks, CA: Sage.

Martin, J. J., \& Kulinna, P. H. (2004). Self-efficacy theory and the theory of planned behavior: Teaching physically active physical education classes. Research Quarterly for Exercise and Sport, 75, 288-298.

Martin, J. J., \& Kulinna, P. H. (2005). A social cognitive perspective of physical-activity-related behavior in physical education. Journal of Teaching in Physical Education, 24, 265-281.

Meegan, S., \& MacPhail, A. (2006). Irish physical educators' attitude toward teaching students with special educational needs. European Physical Education Review, 12(1), 75-97. http://dx.doi.org/10.1177/1356336X06060213

Merriam, S. B. (2009). Qualitative research: A guide to design and implementation (Revised and expanded from qualitative research and case study application in education). San Francisco: Jossey-Bass.

Morley, D., Bailey, R., Tan, J., \& Cooke, B. (2005). Inclusive physical education: teachers' views of including pupils with special educational needs and/or disabilities in physical education. European Physical Education Review, 11(1), 84-107. http://dx.doi.org/10.1177/1356336X05049826

Obrusnikova, I. (2008). Physical educators' beliefs about teaching children with disabilities. Perceptual and Motor Skills, 106, 637-644. http://dx.doi.org/10.2466/pms.106.2.637-644

Patton, M. Q. (2002). Qualitative research and evaluation methods. Thousand Oaks, CA: Sage.

Rizzo, T. L., \& Vispoel, W. P. (1991). Physical educators' attributes and attitudes toward teaching students with handicaps. Adapted Physical Activity Quarterly, 8(1), 4-11.

Sato, T., \& Hodge, S. R. (2009). Japanese physical educators' beliefs on teaching students with disabilities at urban high schools. Asia Pacific Journal of Education, 29(2), 159-177. 
http://dx.doi.org/10.1080/02188790902857164

Sato, T., Hodge, S. R., Murata, N. M., \& Maeda, J. K. (2007). Japanese physical education teachers' beliefs about teaching students with disabilities. Sport, Education and Society, 12(2), 211-230. http://dx.doi.org/10.1080/13573320701287536

Schaaf, M. F. v. d., Stokking, K. M., \& Verloop, N. (2008). Teacher beliefs and teacher behavior in portfolio assessment. Teaching and Teacher Education, 24, 1691-1704. http://dx.doi.org/10.1016/j.tate.2008.02.021

Smith, A. (2004). The inclusion of pupils with special educational needs in secondary school physical education. Physical Education and Sport Pedagogy, 9(1), 37-54. http://dx.doi.org/10.1080/1740898042000208115

Stainback, S., \& Stainback, W. (1990). Inclusive school. In W. Stainback \& S. Stainback (Eds.), Support networks for inclusive schooling. Baltimore: Paul H. Brookes.

Stroot, S. A. (1996). Organizational socialization: factors impacting beginning teachers. In S. J. Silverman \& C. D. Ennis (Eds.), Student learning in physical education: applying research to enhance instruction (pp. 339-365). Champaign, IL: Human Kinetics.

Sugar, W., Crawley, F., \& Fine, B. (2004). Examining teachers' decisions to adopt new technology. Educational Technology and Society, 7(4), 201-213.

The Hong Kong Government. (1977). Integrating the Disabled into the Community: A United Effort.

To, S.-M. (2007). Empowering school social work practices for positive youth development: Hong Kong experience. Adolescence, 42(167), 555-567.

Tripp, A., \& Rizzo, T. (2006). Disability labels affect physical educators. Adapted Physical Activity Quarterly, 23(3), 310-326.

Wong, K. P. D., Pearson, V., \& Lo, M. K. (2004). Competing philosophies in the classroom: a challenge to Hong Kong teachers. International Journal of Inclusive Education, 8(3), 261-279. http://dx.doi.org/10.1080/13603110320000160599

Yuen, M., \& Westwood, P. (2001). Integrating students with special needs in Hong Kong secondary schools: teachers' attitudes and their possible relationship to guidance training. International Journal of Special Education, 16(2), 69-84. 